\title{
EXERCÍCIOS DE AUTORIDADE DO PROFESSOR EM SALA DE AULA
}

\author{
J. F. FLORES, J. B. ROCHA FILHO, L. F. MARQUES, R. M. RIGO \\ Universidade Federal do Rio Grande do Sul/UFRGS \\ jose.flores@ufrgs.br*
}

Submetido 11/05/2016 - Aceito 20/11/2018

DOI: $10.15628 /$ holos.2018.4554

\section{RESUMO}

Este ensaio apresenta discussões teóricas sobre a procurando-se aprofundar na definição do papel do autoridade do professor em sala de aula. A questão a ser tratada é qual a melhor atitude a ser assumida pelo professor diante de uma situação em que identifica uma ação inadequada de aluno em sala de aula. É relatado um caso real ocorrido em sala de aula e discutidos posicionamentos de alguns autores que tratam do tema docente em sala de aula. Conclui-se que a autoridade do professor fica estabelecida a partir da forma como se relaciona com seus alunos, de suas competências na área de conhecimento e na capacidade de enfrentar situações que exigem criatividade e atitude reflexiva.

PALAVRAS-CHAVE: ensino e afetividade, autoridade docente, competência e autoridade, autoridade e afetividade.

\section{TEACHER'S AUTHORITY PRACTICES IN THE CLASSROOM}

\begin{abstract}
This paper presents theoretical discussions about the teacher's authority in the classroom. The question to be addressed is about the best teacher's attitude in front of inadequate action student in classroom. A real case in the classroom is reported and discussed positions of some authors who deal with the subject looking to
\end{abstract}

deepen the definition of the teacher's role in the classroom. We conclude that the teacher's authority is established from the way they relate to their students, their skills in the area of knowledge and ability to face situations that require creativity and reflective attitude.

KEYWORDS: education and affectivity, teaching authority, competence and authority, authority and affection. 


\section{INTRODUÇÃO}

A crise de autoridade não é um tema novo nas sociedades ocidentais. O abuso de autoridade e de poder, de formas violentas, talvez tenha gerado a consciência de que a democracia e as relações mais horizontalizadas seriam formas possivelmente mais harmoniosas de se viver coletivamente. A obediência e a submissão já não são um tema central quando se fala das relações professor-aluno e pais-filhos. As relações passaram a ser negociadas. Uma autora emblemática dessa ideia é Hannah Arendt que vivenciou o abuso de poder ao ser expulsa do seu país (STOLCKE, 2002) e propõe um conceito de poder que implica consentimento ao invés de obediência ou violência.

Em um dos encontros de uma disciplina de pós-graduação em educação em ciências, iniciamos um debate sobre a autoridade do professor em sala de aula, e várias observações se estabeleceram a respeito. As interrogações passaram a suscitar diferentes apontamentos e reflexões, culminando no foco da questão, os limites em sala de aula. Será que um professor pode e deve impor limites de comportamento a seus estudantes, ou, se esta determinação pode ser autóctone do grupo de estudantes para que se desenvolva um ambiente adequado de aprendizagem? Um dos colegas presente, apresentou a seguinte situação vivida por ele. Na volta do recreio alguns estudantes trouxeram parte de seus lanches na mão. Um dos estudantes, ao entrar na sala, jogou no chão o papel que trazia. O professor, observando o ocorrido, alertou o estudante, de forma cordial, para que juntasse o papel. Este respondeu dizendo que não precisava fazer isso, pois na escola existem pessoas pagas para realizarem essa tarefa. A partir desse relato ficamos todos perplexos com a resposta do aluno, e algumas manifestações de indignação aconteceram no grupo. Como pode um estudante dar uma resposta dessas? Ele deve ter aprendido essa postura em casa. Será que seus pais não o ensinaram? Se fosse em minha aula ele não faria isso. Eu o faria juntar o papel na mesma hora.

Esses e outros comentários foram surgindo entre os pós-graduandos até que o professor tomou a palavra questionando qual seria a melhor atitude para gerir essa situação de classe - o gesto mais indicado visando que o acontecimento se transformasse em um momento de aprendizado para esse estudante e para seus colegas. Um dos pós-graduandos se manifestou dizendo que solicitaria gentilmente ao estudante que juntasse o papel, lembrando que se todos tivessem essa atitude a sala se tornaria um grande cesto de lixo e, além do mais, as pessoas responsáveis pela limpeza seriam sobrecarregadas em seu trabalho. Outros pós-graduandos apresentaram opiniões mais ou menos nessa mesma linha de argumentação. O professor, então, concordou que essa seria uma forma possível de encaminhar a situação, mas que talvez existissem maneiras de resolver o caso, até mesmo sem que nenhuma palavra tivesse que ser dita.

Ele relatou que um fato semelhante havia acontecido com ele, em uma época em que trabalhava com séries do final do ensino fundamental. Ao ver que um dos estudantes jogara um papel no chão, caminhou calmamente até o lugar, enquanto respondia uma pergunta de outro estudante, e o juntou, levando-o até o lixo, sem interromper a aula e continuando as atividades com naturalidade, sem sequer olhar para o estudante de uma forma crítica. Esse simples gesto fez com que aquele estudante, e os demais da mesma turma, jamais jogassem novamente qualquer 
lixo no chão durante aquele ano letivo, e que surgisse uma espécie de auto regulação no grupo quanto a esse aspecto da conduta escolar. Um resultado assim, pode ser explicado a partir de diversas perspectivas, mas ao contrário do que pode parecer, já que o gesto sugere humildade, qualquer uma delas implica que o professor tenha autoridade. Mas que autoridade seria essa, e qual seria a melhor forma de expressá-la?

Todo o grupo da disciplina de pós-graduação, profissionais experientes, nos surpreendemos com a atitude do professor, e nos calamos, refletindo sobre o relato. Sentimo-nos desafiados diante de uma solução incomum e até inesperada, mas de um potencial educativo que se mostrou maior do que aquele que seria o de chamar a atenção do aluno diante de seus colegas. A partir daí começamos a refletir sobre quantas vezes enfrentamos situações desafiadoras e nos conformamos em repetir soluções antigas que aprendemos com experiências passadas e outras épocas da vida, e que não estão adequadas ao contexto atual. Os modelos que tivemos nos capacitaram a certo tipo de atitude que retiramos de nosso baú de soluções, e que tendemos a aplicar de forma automática sem observar que os contextos mudam, e que as novas gerações possuem outras características. Algumas destas reflexões trazemos a seguir. Este artigo é um ensaio teórico sobre o tema da autoridade na docência suscitado por uma discussão surgida numa disciplina de pós-graduação.

\section{A QUESTÃO DA AUTORIDADE DO PROFESSOR EM SALA DE AULA}

Quando se propõe a discussão sobre autoridade do professor, necessariamente se deve remeter a questões voltadas para os objetivos da educação. A autoridade do professor está vinculada aos processos de aprendizagem que vão além de considerações a respeito de sua área de conhecimento. Não resta dúvida que as competências a serem desenvolvidas e o acesso a conhecimentos específicos, fazem parte das atividades docentes e devem estar sempre presentes como elementos de formação (IMBERNÓN, 2011). Quando são propostas estratégias e objetivos para a educação, procura-se que estejam a serviço de formação integral do indivíduo nos termos em que são apresentados nas diretrizes básicas para a educação nacional:

Educar exige cuidado; cuidar é educar, envolvendo acolher, ouvir, encorajar, apoiar, no sentido de desenvolver o aprendizado de pensar e agir, cuidar de si, do outro, da escola, da natureza, da água, do Planeta. Educar é, enfim, enfrentar o desafio de lidar com gente, isto é, com criaturas tão imprevisíveis e diferentes quanto semelhantes, ao longo de uma existência inscrita na teia das relações humanas, neste mundo complexo. Educar com cuidado significa aprender a amar sem dependência, desenvolver a sensibilidade humana na relação de cada um consigo, com o outro e com tudo o que existe, com zelo, ante uma situação que requer cautela em busca da formação humana plena (Brasil, 2013, p.18).

Estes aspectos clarificam e ratificam nosso entendimento acerca da postura a ser adotada pelo professor, "uma postura mediadora", onde direitos e deveres precisam ser explicitados desde o início. Assim como outras profissões, o professor também recebe, no ato da formatura na licenciatura, um título reconhecido pelo Estado que lhe garante certas prerrogativas, às vezes confundidas com autoridade, mas de fato sua autoridade não advém deste título. Quando os estudantes recebem um professor desconhecido em suas classes, no primeiro dia de aula de certo 
período letivo, este professor não tem qualquer autoridade sobre esses estudantes, independentemente do nível de ensino e do tipo de sistema escolar. Cabe a ambos criar esse novo relacionamento, mas considerando que ao professor cabe tomar a maior parte das iniciativas, incluindo "dar o tom" no relacionamento professor-aluno (AQUINO, 1996). Para os estudantes, os momentos iniciais da relação educativa são de expectativa, de esperança de que aquele professor não seja simplesmente mais um a ser esquecido. Todavia, expectativa similar também é relatada por alguns professores diante de uma nova turma de alunos. Diante desta dual expectativa cabe ao professor estabelecer diretrizes para garantir a equidade no aprendizado.

O professor que alcança autoridade perante seus alunos é aquele que se conhece, que sabe de suas potencialidades e de seus limites, que avalia permanentemente suas ações, sabe voltar atrás e desculpar-se ou justificar seu engano, e sabe que não há razões para ter medo (ROCHA FILHO, BASSO; BORGES, 2007). Ele também relaciona os diversos aspectos da ação docente, enxergando-a como um todo, e sabe que sua função é levar os alunos a se conhecerem e, para isso precisa amá-los. Em síntese, toda autoridade útil de um professor emana naturalmente da boa relação com seus alunos, tornando-o um modelo e um líder natural, influenciando positivamente seus estudantes no desenvolvimento da própria identidade. Valida a referência sobre a importância do modelo García (2005), ao acrescentar que:

Aprender a ensinar é um processo que se inicia através da observação de mestres considerados "bons professores", durante um período de tempo prolongado. Isto significa trabalhar com um mestre durante um determinado período de tempo ao longo do qual o aprendiz adquire as competências práticas e aprende a funcionar em situações reais. (Garcia, 2005, p. 39).

Todavia, para cada situação que venha a ocorrer no contexto educacional, cabe a cada professor avaliar com rigor e sutileza o que a situação apresenta. Pensando pelo viés otimista e como grande aposta nesta área de atuação, a educação é atribuída a responsabilidade para resolver grande parte das mazelas do mundo. Fraquejar ou desistir frente as dificuldades educativas é perder a crença no ser humano ou mesmo atestar que este ser humano está fadado ao fracasso.

A imagem do que é ser professor, do que faz um bom professor, aliado como as expectativas que a escola, os pais e a sociedade têm sobre seu papel, imprimem certas limitações e potencialidades no ambiente escolar. Nos educandos as consequências não se limitam à potencial possibilidade de imitação por parte dos alunos, mas os levam à reflexão sobre suas ações, já que o professor é alguém que tem poder na sala de aula. Respalda nossa argumentação Westbrook quando acrescenta que:

a grande recompensa do exercício da capacidade de pensar é que não há limites para a possibilidade de transmitir a objetos e acontecimentos da vida significações originalmente adquiridas por exame mediato; e, por conseguinte, não há limites para o desenvolvimento contínuo do significado na vida humana (Westbrook 2010, p. 115).

No caso do aluno que joga um papel no chão, chamar sua atenção diante de seus colegas dificilmente se constituiria em atitude educativa, pois é mais provável que a admoestação pública, 
o leve a conter-se simplesmente pela vergonha. E, ao sentir-se julgado por seus colegas, por mais comedido que tenha sido o docente em suas palavras, gestos e entonação de voz o aluno pode revoltar-se contra seu professor, culpando-o pelo constrangimento que sentiu. Esse processo do estudante normalmente é inconsciente, gerando complexos que eventualmente emergem em prejuízo do processo educativo. No entanto, ao recolher o papel que o aluno jogou no chão o professor não só deu um exemplo de civilidade, mas propiciou sutilmente condições para que o aluno e seus colegas se voltassem a uma reflexão sobre seus comportamentos. Especialmente grande é o impacto de uma ação inesperada que foge ao papel prescrito que um professor deveria desempenhar. E ilustra da melhor forma o que Aquino (1996) aponta como a educação como prática social e como compromisso político do professor que assume a parábola do mestre como exemplo.

É um caso típico, no qual ações repressivas podem produzir efeitos contrários aos propósitos da educação. Neste sentido, corrobora Nóvoa (2011, p.31) quando se manifesta acerca da autoridade em sala de aula, afirmando que "conquista-se através de um esforço continuado de nos darmos ao respeito, de construirmos o espaço educativo como um lugar de diálogo e de trabalho". Todavia reconhece que vivemos em tempos de muita incerteza e insatisfação. Entretanto não desanima frente às dificuldades, e procura encontrar alternativas para promover as mudanças necessárias. Reconhece a fragilidade que o campo educacional tem enfrentado, mas acredita que estas dificuldades nos obrigam, enquanto professores, a um "exercício de modéstia e humildade".

Apesar de perspectivas pouco otimistas, Nóvoa (2011) nos convida a repensar a profissão docente, apontando para três elementos a analisar: a Pessoa, a Partilha e a Prudência. Analisar a pessoa no sentido de compreender a diversidade a singularidade do ser. Atribuir uma atenção especial à partilha no sentido do acolhimento ao aluno diferente, à relação com o outro e ao trabalho cooperativo. Por fim, porém não menos importante a prudência, num duplo sentido: social e científico. Acredita que, apesar das inúmeras dificuldades, a educação continua a acontecer, mesmo quando relativiza conhecimentos e valores. Mesmo assim, acredita que vale a pena ensinar tudo o que une e tudo o que liberta, e enfatiza:

Ensinar exige maestria, competência e tacto pedagógico. A organização das situações de aprendizagem, a progressão dos alunos ou a concepção de dispositivos de diferenciação pedagógica são tarefas muito complexas. Ensinar só é fácil para quem nunca entrou numa sala de aula (Nóvoa, 2011, p.74).

Neste universo complexo repleto de constantes mudanças, de comportamentos questionáveis, ou inaceitáveis, o ato de ensinar deve estar impregnado de saberes e valores éticos, o que implica em ações que abarquem todas as dimensões do ser humano. Tais prerrogativas é que poderão impulsionar e despertar no aluno um comportamento coerente para consigo e para com todo o universo em que habita (dentro e fora da sala de aula), evitando assim, a necessidade de ações mais radicais ou repressivas.

De fato, a repressão é um recurso último, que implica exercício de poder instituído, sendo intrinsecamente alheia à educação que tem fundamentos qualitativamente diferentes e que incluem o exemplo, a empatia, o autoconhecimento, o acolhimento, a investigação, a comunicação 
e a reflexão. Ao contrário, a repressão demanda aparelhos por meio dos quais o poder é exercido, e a escola não possui ou faz parte desses aparelhos, pois seus meios e fins são absolutamente distintos.

No caso anedótico analisado nesse texto, outra possibilidade é argumentar que, vendo o professor juntar o papel do chão, outros alunos possam criticar seu colega e produzir nele igual perturbação que a da admoestação magistral, mas isso é pouco provável. Neste caso, seria estabelecida uma relação entre iguais na cadeia hierárquica escolar, criando uma possibilidade menor de constrangimento ao aluno, pois este pode se justificar aos colegas, evitando que parta do professor qualquer advertência. Porém, esta busca por igualdade na cadeia hierárquica, pode ser interpretada de diferentes maneiras, conforme contextualiza Nietzsche, já que para este autor existem dois tipos de igualdade: "A ânsia de igualdade pode se expressar tanto pelo desejo de rebaixar os outros até seu próprio nível (diminuindo, segregando, derrubando) como pelo desejo de subir juntamente com os outros (reconhecendo, ajudando, alegrando-se com seu êxito)" (NIETZSCHE, 2000, p. 112).

A atitude do professor, neste caso, certamente seria a de elevar através do exemplo, a consciência do aluno no sentido de sensibilizá-lo, fazer com que reflita sobre o ocorrido, mesmo sem dizer uma palavra, e com isso este aluno possa evoluir gradual e conscientemente. Este processo evolutivo poderá ocorrer para ambos sinergicamente e não unilateralmente, dependendo é claro, do nível de envolvimento, do contexto e do interesse de ambos. Estar em um espaço onde ao ensinar também se aprende como afirma Pecotche (2015, p. 20), "O processo de evolução consciente que você se propõe a cumprir implica a constância de fatos que confirmem essa evolução". Ainda que toda a ação provoque uma reação, neste caso, por mais difícil que possa parecer, recai sobre o professor a responsabilidade maior que é a de transmitir/compartilhar conhecimentos com propriedade e suficiente maturidade, evitando um confronto direto ou um ato punitivo. Neste sentido acrescenta Pecotche (2015), todo ato dirigido conscientemente para o bem só fortalece o ânimo, o estimula e o faz perseverar nessa conduta [...]. Corrobora Nóvoa (2011, p. 76) que "temos de dar tempo à reflexão pessoal, à consciência partilhada, à ação prudente", isto é, inferir saberes e fazeres e aguardar que o tempo e a reflexão cogitada façam sua parte.

Já Arendt (2002) trás reflexões a respeito da atitude de pensar como uma ação que nos leva ao diálogo interior, e consequentemente, conduz a abertura ao diálogo como os demais. Salienta essa filósofa que a capacidade de pensar nos leva a julgar os eventos com os quais nos defrontamos diariamente, desafiando-nos com a seguinte pergunta: "Será possível que o problema do bem e do mal, o problema de nossa faculdade para distinguir o que é certo do que é errado, esteja conectado com nossa faculdade de pensar?" (p. 6). O pensamento, no sentido que Arendt propõe, é a capacidade reflexiva de pôr em questão as próprias convicções e certezas, deslocando-nos do centro para considerar a importância das ações e opiniões dos demais.

Neste sentido a presença do professor como alguém que incentiva nos alunos estes processos reflexivos, poderá levá-los a descobertas sobre si mesmos, percebendo o outro como verdadeiro outro de maneira verdadeiramente igualitária, e não como alguém submisso ou inferior. O professor que realiza o pensar em suas ações estará sendo referência para que seus alunos também realizem esta atitude. Neste contexto acrescenta Westbrook, (2010, p.34), [...] “no 
plano humano, o agir e reagir ganham mais larga amplitude, chegando não só à escolha, à preferência, à seleção, possíveis no plano puramente biológico, como ainda à reflexão, ao conhecimento e à reconstrução da experiência". O exemplo relatado anteriormente atesta esta possibilidade, ou seja, o agir e o reagir como um possível instrumento para compor experiências de aprendizagem. Quanto mais o ser humano for experimentado, mais aguçada poderá ser sua curiosidade, e, consequente, possibilidade de ver, rever e recontextualizar sua trajetória.

Todavia, sabe-se que é muito difícil prever qual a melhor atitude para cada situação que se apresenta no cotidiano escolar, mas a possibilidade de que o exemplo apresentado pelo professor conduza a uma nova e melhor atitude do aluno, parece maior. No caso, o relato do professor nos confirma a eficácia do gesto: "nunca mais aquele aluno jogou papel no chão e não precisei dizer uma única palavra" e acrescenta:

Quando chamamos atenção de alguém perante um grupo, todo mundo fica mal: a pessoa advertida, aquele que está realizando a advertência e as pessoas que estão presenciando. A energia despendida nesta ação é enorme, pois leva todo o grupo a um estado de tensão e isso não faz bem para ninguém, só gera ansiedade. No caso do professor, pode levar o aluno a se defender sentindo-se acuado, pode levar parte do grupo a voltar-se contra o aluno, parte contra o professor. Pode levar o aluno, por sentir medo, a dar uma resposta agressiva ao professor e este se sinta na obrigação de manifestar sua autoridade elevando a voz ou mandando o aluno para fora da aula. Vejam a dimensão que uma ação, supostamente educativa, pode atingir. Vale a pena correr este risco? E não estamos falando de forma hipotética. Isso acontece muitas vezes em nossas escolas.

É evidente que, o relato do professor não consiste em fórmula universal para a solução de situações problemáticas de sala de aula, mas é uma indicação de que para cada situação que se apresenta, podem existir atitudes mais ou menos coerentes com o objetivo educacional, ou seja, concretizar o sentido principal do gesto pedagógico: conduzir, dirigir, inspirar, de forma atenta e criativa. Há certamente muitas respostas para a questão sobre qual seria a melhor ação para cada contexto criado. A questão dos modelos e papéis também remete ao questionamento das atitudes prontas, que levam a comportamentos condicionados, sempre indesejáveis, pois conduzem a deixar de questionar suas ações e reinventar sua prática. Para Meirieu (2005), a missão do professor não é impor modelos e verdades, mas conduzir os alunos para que cheguem a ela. Acrescenta ainda:

Se tentar impor essa verdade pela força, desprezando o rigor do procedimento que conduz a ela, ou simplesmente ordenando que se submetam ao que diz...o próprio princípio de seu magistério desaparece, sua verdadeira autoridade desmorona. [...] Se o professor entrar em uma relação de forças, transformará sua aula em "uma queda de braço[...](Meirieu, 2005, p.52).

É evidente que nossa intenção pedagógica jamais deve ser conduzida ou idealizada com uma simples queda de braço com o aluno. Ao contrário, cabe-nos eliminar todo e qualquer ato que leve a uma violência maior, evitando demonstrar posturas inábeis ou desequilibradas, apesar das circunstâncias, tarefa por vezes árdua no campo do fazer pedagógico contemporâneo. 


\section{NEM AUTORITÁRIO, NEM OMISSO: O PROFESSOR MEDIADOR}

A questão da postura autoritária ou omissa também se manifesta no currículo, na escolha dos conteúdos, materiais e metodologias em sala de aula. Aqui temos um conceito de difícil compreensão e aplicação, já que este entendimento provém principalmente de vivências e reflexões num campo em que as receitas prontas estão fadadas ao insucesso, já que caem rapidamente em desuso. Por isso, muitos professores optam por determinar previamente o que se deve trabalhar em sala de aula, seguindo um posicionamento tradicional de ser professor e acabam desconsiderando as concepções prévias de seus educandos. Quando o professor tem clareza da amplitude da sua função pode ficar mais à vontade para perguntar aos alunos, em determinadas circunstâncias, o que eles gostariam de estudar. Entretanto, neste novo universo educativo em que os papéis de professor e aluno não são rígidos, é fato que os novos alunos muitas vezes apresentam posturas muito diferenciadas, comportamentos intrépidos e posturas inadequadas até como forma de protesto, por estarem frente a uma situação que não sabe o que é dele esperado.

Para este contexto diverso, Nóvoa $(2011$, p. 69) sugere que se "[...] construa uma teoria da pessoalidade no interior de uma teoria da profissionalidade", ou seja, uma construção que também possibilite reconstruir sentido para uma profissão que vive um sentimento de fragmentação. É claro que cada professor, ao abrir espaço para que o aluno possa escolher, necessariamente precisará definir alguns parâmetros, evitando que o aluno apresente sugestões excessivamente distanciadas dos objetivos do espaço educativo. As respostas dos alunos irão mostrar ao professor um pouco do que estes aprenderam em suas vidas, permitindo-o elaborar um plano de ação apoiado nesses conhecimentos prévios. Dessa forma, o professor poderá buscar teorias, organizar métodos e estratégias capazes de desafiar o estudante no ato de inventar caminhos para estudar determinada área de conhecimento. Embasamos esta afirmação em Morin (2005) quando diz que:

Uma teoria não é o conhecimento; ela permite o conhecimento. Uma teoria não é uma chegada; é a possibilidade de uma partida. Uma teoria não é uma solução; é a possibilidade de tratar um problema. Em outras palavras, uma teoria só realiza seu papel cognitivo, só ganha vida com o pleno emprego da atividade mental do sujeito. É essa intervenção do sujeito que dá ao termo método seu papel indispensável (Morin, 2005, p. 335).

Passar uma teoria para os alunos não é gerar conhecimento. A aprendizagem é um processo amplo que requer conhecimento das pessoas envolvidas, professor e alunos. A atitude do professor de conhecer seus alunos exige dele um constante acompanhamento das atividades dos alunos e permanente vigilância, a fim de melhor orientá-los propondo situações que os levarão a questionar suas ações e entendimentos. Poderão assim confrontar suas concepções e confirmá-las ou repensá-las. Este posicionamento ajudará o aluno a voltar-se sobre suas ações, refletindo sobre elas e construindo suas compreensões. Entretanto, vivemos tempos em que paciência e tolerância com processos longos como com o aprendizado lento e maturado, estão se tornando artigos de luxo. Tempos em que a valorização do instantâneo e do imediato é maior. 
Voltando ao caso mote deste ensaio, podemos perceber que o aluno, ao jogar papel no chão, proporcionou uma oportunidade para o professor criar uma situação de aprendizagem. Se no estudante existia uma compreensão prévia de que há pessoas para recolher o lixo, e que isso justificaria o fato de ele abandonar papéis no chão da sala, a atitude do professor criou no aluno a necessidade de repensar seu sistema de crenças, pois certamente ao professor tampouco caberia recolher o papel, mas mesmo assim ele o fez. O estudante tem clareza de que o papel não deve ficar no chão, mas entende que recolhê-lo não é função sua. O professor, por sua vez, captou a compreensão do estudante sobre essa situação e, ao invés da admoestação, optou por uma ação na expectativa de que ele refletisse sobre a própria atitude, sem qualquer crítica externa. 0 professor pode ter feito isso de forma consciente e proposital, desafiando o estudante a desenvolver uma nova forma de perceber a realidade. Por que o professor juntou o papel se existem pessoas para fazer isso? Esta é uma das perguntas que o professor esperou que os alunos fizessem a si mesmos. Outras reflexões poderiam ser: se o professor fez, por que eu não posso fazer? Se todos fizessem como eu a sala ficaria completamente suja? Pôr em prática interrogações desta natureza pode se constituir oxigênio para qualquer proposta de conhecimento, acrescenta Morin (2000).

O professor sabe que há pessoas que realizam a limpeza da escola, portanto seu gesto também sugere o reconhecimento da importância destes profissionais que realizam esse serviço, embora seja também uma tarefa de todos e não algo exclusivo de alguns funcionários. Comumente os alunos nem notam as pessoas que trabalham na limpeza, mas ao perceberem que o professor manifesta afeto e reconhecimento por elas, também esse gesto teria potencial de aprendizagem. Essas reflexões também poderiam ser exploradas quando o contexto é a casa de cada um, o bairro, a cidade, o país, o planeta...

O mestre está (ou deveria estar) muito mais ciente das suas áreas de desconhecimento assim como da sua aposta no processo de aprendizagem tanto seu quanto dos alunos. Deixar aprender e deixar-se aprender. A rigor, ao juntar o papel do chão o professor não tem certeza de nada. Não sabe como o aluno que o jogou vai reagir, e não sabe como seus colegas vão reagir. Talvez no outro dia o aluno repita o mesmo gesto. Talvez o professor vire alvo de chacotas dos alunos por ter recolhido o papel e o colocado no lixo. Talvez outros alunos decidam atirar também seus papéis ao chão para ver a reação do professor. Tudo depende de quem é aquele professor, e o que significa aquele professor para aqueles estudantes. Mas existe alguma possibilidade de os alunos calarem em relação a essa atitude e pensarem sobre o impacto de suas ações. Este risco, o professor que reflete sobre sua influência, deve arriscar. E ao correr o risco, o professor estará aprendendo e mostrando aos alunos sua abertura ao novo. O que seria o aprender se não houvesse abertura e curiosidade pelo desconhecido? Estará conhecendo mais seus alunos e a si mesmo. Poderá refletir sobre sua própria ação e, caso não aconteça o que ele espera, pensará em nova estratégia.

Quando sua intenção está voltada para criar condições para que o aluno aprenda, este professor estará aprendendo de forma cada vez mais profunda sobre o ato de ensinar e sobre si mesmo, conhecendo-se. Se for alvo de chacota poderá refletir: o que existe nesse relacionamento com meus alunos que faz com que eles não tenham respeito por mim? Qual ou quais atitudes 
minhas levaram os alunos a terem esse comportamento? Que receios carrego que me impedem de estabelecer uma relação de aprendizagem em sala de aula? O processo de aprender é múltiplo e ocorre em várias direções.

Outra possibilidade é a de que o aluno, ao perceber que o professor se dirige para recolher o papel, se antecipe, pegue-o antes dele e o coloque no lixo. Ou mesmo um simples olhar do professor pode ser suficiente para que o aluno se dê conta de seu equívoco. Neste caso, novamente é o professor o que mais aprende, pois pode perceber que é preciso criar condições para a tomada de consciência evitando os extremos de ser autoritário ou omisso. É preciso dar tempo ao aluno para repensar suas convicções, suas concepções, ou simplesmente considerar a possibilidade de um descuido do aluno. Isso se aplica igualmente em situações de aprendizagem de conteúdos formais a respeito de sua área de conhecimento.

Os alunos se relacionam com o conteúdo trabalhado de forma similar com que se relacionam com o seu professor. A ligação afetiva é fator fundamental para o aprendizado. Todo aprendizado possui um componente afetivo que o faz acontecer. Por ter estabelecido uma relação de cordialidade com seus alunos desde o começo do ano letivo, estes dificilmente se sentirão ofendidos quando o professor, com seu exemplo, convidá-los a refletir. E quando a relação professor-aluno se baseia no diálogo, na confiança e na solução democrática dos conflitos, a afetividade se fortalece e a relação de autoridade pode se exercer pelo respeito e admiração dos alunos. Dessa forma, o que prepondera não é o medo da punição, mas o receio de perder o respeito da pessoa admirada, no caso o professor (CARNEIRO, 2015).

Criar elos de ligação e vínculos afetivos é premissa básica para que processos de ensino e aprendizagem possam ocorrer de maneira satisfatória. Ganha em qualidade e efetividade aquele professor que consegue estabelecer esta ponte entre o aluno e o conhecimento. E este vínculo se estabelece a partir de uma mediação coerente, oferecendo as ferramentas e condições prévias necessárias para que o desenvolvimento possa ocorrer. Outra situação que possibilita o estreitamento dos vínculos são as atividades colaborativas. Tais atividades permitem que cada um atue a partir de seus pontos fortes, e estes pontos fortes quando unidos fazem emergir capacidades muitas vezes ainda ocultas.

Dentre os estudos e pesquisas realizados por Reuven Feuerstein (1921-2014), destacamos aqui excertos que chancelam resultados efetivos referentes à Teoria da Experiência de Aprendizagem Mediada. Para o referido autor, quando se trabalha a aprendizagem de forma mediada no cotidiano escolar, enriquecemos as interações, desde que, tal mediação, seja fundamentada na crença da capacidade do ser humano de modificar-se, independentemente de origem, idade ou condição genética. Compartilha deste entendimento Souza et. al. (2003, p. 37), quando acrescenta que: "a modificabilidade está diretamente relacionada com a qualidade de mediação e com os processos cognitivos e afetivos de uma pessoa. Pela mediação, atingimos os dois maiores fenômenos do ser humano: modificabilidade e diversidade". Dentre os 12 critérios de mediação elaborados por Feuerstein, os três primeiros, conforme Tébar (2011, p. 93), são: “a intencionalidade, a transcendência e a significação que estão presentes em todas as culturas, criam modificabilidade, flexibilidade, capacitam para a mudança". A mediação neste sentido deve ser um processo intencional que estimule a busca de significado do que está sendo proposto, e instigue o 
desejo de saber mais, promovendo elaborações e (re)elaborações mais profundas e duradouras.

\section{A TRANSPOSIÇÃO DE LIMITES PELA AÇÃO}

Quando nos atemos somente na observação de objetos isolados entre si, visualizamos o mundo de modo estanque, congelado em imagens estáticas. Na situação de sala de aula discutida neste artigo, o papel no chão é um momento, e papel no lixo é outro momento. Dessa forma, ficamos cegos aos movimentos. A inteligência, configurada para respostas certas e definitivas a partir de ensino meramente transmissivo, tende a se fixar em momentos, em repousos, em resultados, enquanto a natureza do mundo é a ação, o vir-a-ser que cria o tempo. Por isso a educação falha quando projeta alvos objetuais ou ontológicos, mas tem sucesso quando se deixa levar pela intuição, pela arte, pelos movimentos, procurando desvelar e valorizar os processos, mais que os fins. Refletir e focar no processo em si ou na forma como são conduzidas nossas ações e a de nossos alunos, é estar cientes de que, enquanto refletimos poderemos estar revendo posturas e formas de fazer a ação. Neste sentido, corrobora Zeichner (1993), quando nos diz que:

A reflexão é um processo que ocorre antes e depois da ação e, em certa medida, durante a ação, pois os práticos têm conversas reflexivas, são as situações que estão a praticar, enquadrando e resolvendo problemas in loco. (...) Para além do saber na ação que vamos acumulando ao longo do tempo, quando pensamos no nosso ensino quotidiano, também estamos continuamente a criar saber (Zeichner, 1993, p. 19).

Todavia, entendemos que a reflexão por si só perde o sentido se não vier acompanhada da ação. É necessário refletir e (re)agir para não sermos considerados apenas técnicos que se limitam a repetir o que outros ditam, ou apenas sermos participantes passivos no processo educativo. Nessa mesma esteira de reflexão, Donald Schön (2000), fundamenta seu trabalho apoiado nos pressupostos de John Dewey e embasa-se nos conceitos de conhecimento, de ação e reflexão na ação, enfatizando que a aprendizagem ocorre pelo fazer. Para Schön (2000), o conhecimento na ação é o componente que está diretamente relacionado com o saber-fazer; é espontâneo, implícito e surge na ação, sendo, então, um conhecimento tácito. $O$ ato de refletir sobre a ação nos permite considerar no ato em si: porque agimos, e como fizemos aquilo que estamos explorando, projetando, executando em um grupo, e assim por diante.

Ao projetarmos uma ação educativa, partimos do pressuposto que antes disso esta ação tenha sido idealizada, rememorada e possivelmente reescrita algumas vezes, mesmo que em pensamento ou através de partilhas entre iguais. Estas tentativas podem ser aproximadas às ideias educacionais de Dewey (1859-1952) quando diz que existe profunda relação entre a necessidade de filosofar e a de educar. Esta necessidade encontra-se intimamente vinculada ao campo educacional, ao campo das relações humanas que permeiam nosso cotidiano; relações estas muitas vezes marcadas pela intolerância, pelo desrespeito e pela agressão.

Se por um lado temos alunos ávidos por aprender, por outro temos muitas vezes que conviver com situações muito distantes do ideal. Neste caso, existe a necessidade de comprovar bons pensamentos por meio de ações que resultem em conhecimento, sempre utilizando o 
diálogo franco como alicerce para tais interações, sejam crianças ou adultos. Para Westbrook (2010, p. 41) "a influência do adulto sobre a criança se exerce por meio de processos tão complexos, acidentais e amplos, que é impossível sistematizá-los, organizá-los, ou mesmo fixarIhes os limites". Neste emaranhado de possibilidades filosofar, argumentar ou contextualizar para educar, são certamente premissas básicas para instrumentalizar os processos do ensinar e do aprender, todavia, sem sair dos limites democráticos para uma simbiose adequada e produtiva.

Fala-se tanto em dar limites, impor limites. Porque não falar em transpor limites? Sabemos que não se dá limites a ninguém. Será que o certo seria dizer impor limites? Mas, evitamos essa expressão porque na contemporaneidade a imposição soa maligna. É preciso refazer a pergunta: devemos e podemos impor limites a alguém? Devido à natureza ambivalente dos seres humanos, em parte racionais e em parte irracionais, capazes da bondade e do amor, assim como do medo, da inveja e da violência, a vida social sem dúvida exige limites. Mas, esses limites são dados pelas leis e seus aparelhos institucionais. Aqui, estamos discutindo a educação formal. Trata-se dos mesmos seres, mas vistos quanto a um aspecto muito particular da vida. Dessa forma, seria melhor ser ainda mais específico: pode e deve um professor estabelecer limites de ação a seus alunos?

Sob uma concepção fundada no senso comum talvez disséssemos que aquele aluno que jogou o papel no chão está precisando de limites ou que seus pais não the deram limites. É claro que há limites e que esses limites se referem fundamentalmente ao respeito mútuo na relação com o outro ou com os outros, no sentido mais amplo. Os limites são naturalmente flexíveis, pois dependem das pessoas, das épocas e das situações, e mesmo a ética perene precisa ser interpretada. Se nos ativermos ao caso em questão, e à suposição de que o estudante precisa de limites, e que dá-los é também papel do professor, isso poderá nos conduzir a uma atitude repressora, materializada, por exemplo, na ordem para que o estudante recolha o papel do chão e, caso ele se negue, no seu encaminhamento ao setor disciplinar da escola e todas as demais consequências regimentais institucionais. Esse processo repressivo pode até resultar em aprendizagem, mas dificilmente seria o tipo de aprendizagem que idealmente deseja o professor. É mais provável que o estudante aprenda que não deve deixar que o vejam cometendo infrações às regras escolares, que seu professor o valoriza menos do que a limpeza do chão e o cumprimento de normas, e que seu professor é capaz de exercer seu poder instituído humilhando-o perante seus colegas e denunciando-o a outras instâncias escolares. Indubitavelmente, houve aprendizagem carregada de afetividade.

Mas, é essa aprendizagem que queremos? Isso é educar? Ademais, o que o professor aprendeu com isso? Que criatividade usou para resolver essa situação? Estaria agora o professor mais capacitado a lidar com situações semelhantes que certamente ocorrerão no futuro? E se o simples algoritmo repreensão-encaminhamento eventualmente resultar no afastamento permanente do estudante? Esse professor desempenhará melhor sua tarefa educativa? Estará satisfeito por contribuir para a exclusão de mais uma pessoa do sistema educativo? E se o estudante for simplesmente recolocado em sala de aula após um curto intervalo de tempo, como costuma acontecer, agora com desejo consciente ou inconsciente de prejudicar seu professor da forma que puder? Em que isso pode ser benéfico ao professor ou à educação? 
Se o aluno fosse muito jovem e susceptível, ou muito tímido, por exemplo, também poderia ocorrer que ele nunca mais jogasse papel no chão apenas por medo de receber punições. Neste caso também não haveria aprendizado, pois não ocorreu tomada de consciência, não aconteceu um voltar-se sobre si mesmo avaliando suas ações. Não se caracterizou um conhecer-se. Corrobora Westbrook (2010, p. 57) quando argumenta que se aprende pela "reconstrução consciente da experiência, isto é, as experiências passadas afetam a experiência presente e reconstroem para que todas venham influir no futuro", pois só se aprende o que se pratica. E, somente em situações reais de vida onde se tenha que demonstrar traços de caráter, é que estes traços podem levar a práticas recorrentes, e consequentemente, a novas aprendizagens.

\section{A QUESTÃO DA AUTORIDADE}

Refletir sobre o conceito de autoridade e como deve ser exercida, corresponde a pensar sobre o ser social e individual da pessoa. A autoridade, para além da ideia de hierarquia, está relacionada à atitude de respeito ao outro. E quando o professor se põe a analisar suas funções e responsabilidades acaba por realizar diálogo interior no caminho do autoconhecimento (ARENDT, 2002).

Esse processo reflexivo acarreta no colocar em questão seus pressupostos, crenças e certezas. Tal atitude o levará a, aos poucos, identificarem si mesmo ações produzidas de forma automática, sem reflexão. Assume, sem perceber, posturas para as quais não construiu significados. Não se torna autor de si mesmo. Reproduz apenas um modo de ser e estar no mundo que foi incorporado ideologicamente, sem uso do pensar (ARENDT, 2002). Imbernón (2011) salienta que o professor que não realiza movimento de analisar a si mesmo aceita a falsa premissa de que [...] se trata de uma profissão incapaz de criar conhecimento profissional, que se limita a reproduzir cultura e o conhecimento que outros cultivaram e desenvolveram (p.117).

A formação das próprias compreensões não se constitui como atitude individual, solitária. A superação de concepções dogmáticas e atitudes pré-fabricadas acontece pela percepção de si como ser social, cultural, histórico e psicológico. Todo aprendizado é cooperativo, interativo e integrador. Com este viés na formação docente, vários autores têm sugerido a investigação como princípio formativo (HERNÁNDEZ, 1998; DEMO, 2002; IMBERNÓN, 2011). O modelo da pesquisa na formação supõe a capacidade de formular questões válidas sobre a própria prática. A partir daí elaborar de forma colaborativa e criativa, objetivos que possam trazer novas compreensões sobre tais questões.

Por estes movimentos se poderá perceber que a autoridade exigida na educação subentende, um professor que vai adquirindo autoconfiança, que constrói uma visão positiva de si mesmo, ao mesmo tempo em que é responsável por sua área de conhecimento. Portanto deve, permanentemente, estar questionando os conceitos e modos como esses conhecimentos foram se constituindo patrimônio da humanidade.

Autoridade docente não significa poder de controle e fiscalização para manter o aluno quieto e concentrado. Antes requer profundidade nos conhecimentos que apresenta aos alunos como desafios. Também exige a segurança sobre os motivos e objetivos que o levaram a se 
dedicar a essa profissão. Por isso as ações em conjunto, as trocas e dúvidas, a participação de todas as instâncias da instituição se configura como fator definitivo para o relacionamento afetivo e de respeito do professor com seus alunos. Conforme afirma Imbernón

Quando os professores trabalham juntos, cada um pode aprender com o outro. Isso os leva a compartilhar evidências e informação e a buscar soluções. A partir daqui os problemas importantes das escolas começam a ser enfrentados com a colaboração entre todos, aumentando as expectativas que favorecem os estudantes e permitindo que os professores reflitam sozinhos ou com os colegas sobre os problemas que os afetam. (Imbernón, 2011 p. 82)

Tais considerações nos indicam possibilidades de construção de professores que realizam a autoria da própria profissão e são capazes de avaliar suas ações percebendo nos alunos sujeitos que serão autores de sua história.

\section{CONSIDERAÇÕES FINAIS}

Pelo acima exposto a partir das discussões e dos autores apresentados, percebemos que o que desencadeia a aprendizagem é a afetividade, e que ela desperta o desejo de conhecer e prepara o ambiente para a curiosidade. Desse modo, se o aluno gosta do professor é muito provável que gostará também da disciplina que aquele ministra, e se interessará mais por estudar os conteúdos propostos. Se o professor não estabelecer uma relação de respeito e afetividade com os seus alunos a partir de aspectos simples do cotidiano, combinando as regras de convivência, dificilmente colaborará para o despertar da motivação dos estudantes para suas propostas de estudos.

A ação do professor em aula e fora dela faz parte de um todo, que caracteriza a personalidade do professor e que os alunos percebem claramente, ainda que não consigam verbalizá-lo. Eles compreendem a autoridade do professor como decorrente de diferentes capacidades, incluindo principalmente sua empatia, o domínio de sua área de estudo, a preparação de aulas, a segurança emocional que manifesta, em que grau suas atitudes podem servir de exemplo de conduta, e se ele é feliz.

Almejar que este conjunto de preceitos possam ser atingidos plenamente em todos os momentos soa com utopia, porém o que seriam dos sonhos se ao menos vez ou outra não pudéssemos trabalhar exaustivamente neles para transformá-los em realidade.

\section{REFERÊNCIAS}

Aquino, J. G. (1996). Confrontos na sala de aula: uma leitura institucional da relação professor aluno. Summus.

Arendt, H. (2002). A vida do espírito: o pensar, o querer e o julgar. Rio de Janeiro: Relume Dumará. Brasil. (2013). Ministério da Educação. Secretaria de Educação Básica. Secretaria de Educação Continuada, Alfabetização, Diversidade e Inclusão. Diretrizes Curriculares Nacionais Gerais da Educação Básica / Ministério da Educação. Secretaria de Educação Básica. Diretoria de 
Currículos e Educação Integral. Brasília: MEC, SEB, DICEI.

Carneiro, F. H. P. (2015). Autoridade e disciplina na escola: reflexões sobre de construção da autoridade no contexto de formação de monitores. Cadernos de Estudos e Pesquisa na Educação Básica, v. 1, n. 1, p. 33-45.

Demo, P. (2002). Educar pela Pesquisa. 5a ed. Campinas: Autores Associados.

Feuerstein, R. Feuerstein, S. R. Falik, L. H. (2014). Além da inteligência - Aprendizagem mediada e a capacidade de mudança do cérebro. Petrópolis: Vozes.

Garcia, C. M. (2005). Formação de Professores: para uma mudança educativa. Porto/Portugal, Porto Editora.

Hernández, F. (1998). Transgressão e mudança na educação: os projetos de trabalho. Porto Alegre: ArtMed.

Imbernón, F. (2011). Formação Docente e profissional: formar-se para a mudança e a incerteza. 9 ed. São Paulo: Cortez.

Meirieu, P. (2005). O cotidiano da escola e da sala de aula: o fazer e o compreender, Porto Alegre, Artmed.

Morin, E. (2005). Ciência com consciência. [tradução de Maria D. Alexandre e Maria Alice Sampaio Dória. - Ed. revista e modificada pelo autor - 8" ed. - Rio de Janeiro: Bertrand Brasil.

Morin, E. (2000). Os sete saberes necessários à educação do futuro. tradução de Catarina Eleonora F. da Silva e Jeanne Sawaya ; revisão técnica de Edgard de Assis Carvalho. - 2. ed. - São Paulo: Cortez; Brasília, DF : UNESCO.

Nietzcsche, F. (2000). Humano, Demasiado Humano. Editora Schwarcz Itda, São Paulo.

Nóvoa, A. (2011). O regresso dos professores, Lisboa.

Pecotche, C. B. G. (2015). Bases para sua conduta: dedicado à juventude [tradução: Colaboradores voluntários da Fundação Logosófica (em Prol da Superação Humana)]. - 22. ed. - São Paulo: Logosófica.

Rocha F. J. B. Basso, N. R. de S. \& Borges, R. M. R. (2007). Transdisciplinaridade: a natureza íntima da educação científica. Porto Alegre: EDIPUCRS.

Schön, D. A. (2000). Educando o Profissional Reflexivo: um novo design para o ensino e a aprendizagem. Trad. para português por Roberto Cataldo Costa. Porto Alegre: Artmed.

Souza, A. M. M. Depresbiteris, L. Machado, O. T. M. (2003). A mediação como princípio educacional: bases teóricas das abordagens de Reuven Feuerstein. 2a ed. São Paulo: Senac.

Stolcke, V. (2002). Pluralizar O Universal: Guerra e Paz na Obra de Hannah Arendt. Rio de Janeiro: MANA 8(1): 93-112.

Tebar, L. (2011). O perfil do Professor Mediador: Pedagogia da Mediação. Traduzido por Priscila Pereira Mota. São Paulo: Ed. SENAC.

Westbrook, R B. John Dewey / Robert B. Westbrook; Anísio Teixeira, José Eustáquio Romão, Verone Lane Rodrigues (org.), (2010). Coleção Educadores, Recife: Fundação Joaquim Nabuco, Editora Massangana.

Zeichner, K. M. (1993). A Formação reflexiva de Professores: ideias e práticas. Lisboa: Educa. 